\title{
A FRAGILIDADE DO MINISTÉRIO DA DEFESA BRASILEIRO
}

\author{
Jorge Zaverucha
}

\begin{abstract}
RESUMO
O presente artigo apresenta os diversos momentos por que passou o Ministério da Defesa, desde sua criação no segundo mandato presidencial de Fernando Henrique Cardoso (1999-2002) até o atual governo de Luís Inácio Lula da Silva (2003-2006), com os respectivos ministros da Defesa. Visto como uma etapa importante na reconstitucionalização do país, na medida em que prevê a submissão dos comandantes das Forças Armadas a um ministro civil, e embora alguns analistas considerem que essa submissão de fato ocorre, procuramos indicar as resistências $e$ as insubordinações militares ao poder civil, provenientes de um legado autoritário. Na medida em que o Ministério da Defesa não consegue implementar uma política própria, em que os militares seguiriam as orientações dos civis, o artigo conclui considerando a fragilidade política e institucional do Ministro da Defesa, civil, ante o os comandos militares, que conservam alto grau de autonomia decisória em relação à estrutura do Ministério.
\end{abstract}

PALAVRAS-CHAVE: Ministério da Defesa; Forças Armadas; democracia; legado autoritário; autonomia decisória.

"O pessimista afirma que já atingimos o fundo do poço. O otimista afirma que dá para cair mais” (Woody Allen).

\section{INTRODUÇÃO}

A falácia da autonomia é a crença na possibilidade de analisar o Ministério da Defesa brasileiro separado do contexto político que o criou. É impossível esperar que tal Ministério atue de acordo com os princípios democráticos se o sistema político não trabalha pela efetiva eliminação do legado autoritário herdado do regime militar ${ }^{1}$. O modo como o Ministério de Defesa funciona no Brasil, já que é influenciado por esse legado, constitui um dos indicadores da fragilidade de nossa democracia.

Escrevi "funciona" porque a criação do Ministério da Defesa per se não é suficiente para

1 “Os legados autoritários são regras, procedimentos, normas, padrões, práticas, disposições, relações e memórias originadas em experiências autoritárias passadas bem definidas que, como resultado de configurações históricas específicas e/ou disputas políticas, sobrevivem à transição democrática e intervêm na qualidade e na prática das democracias pós-autoritárias” (HITE \& CESARINI, 2004, p. 4). garantir que as Forças Armadas estejam submetidas ao controle civil ${ }^{2}$. As Forças Armadas continuam a atuar autonomamente e passam, freqüentemente, por cima da autoridade do Ministro da Defesa, arranhando a autoridade do Presidente da República e em clara insubordinação à cadeia de comando político e militar. Afinal, o Presidente da República é o comandante-em-chefe das Forças Armadas.

\section{A CRIAÇÃO DO MINISTÉRIO DA DEFE- $\mathrm{SA}^{3}$}

A criação de um Ministério da Defesa foi promessa de campanha de Fernando Henrique Car-

\footnotetext{
2 Para visões distintas, vide Carvalho (1999, p. 345): “A criação do Ministério da Defesa vai talvez ser o ponto final do enquadramento das Forças Armadas na vida democrática” e Oliveira (2005, p. 115): "Ministério da Defesa: a implantação da autoridade”.

3 Em 1967, o General-Presidente Castello Branco promulgou o Decreto-Lei n. 200, cujo texto preconizava estudos
} 
doso (FHC). Assim, incumbiu o Ministro-Chefe do Estado-Maior das Forças Armadas (EMFA), General Benedito Onofre Leonel, dessa missão. Essa escolha foi crucial: ela indicava que a concepção do Ministério da Defesa (MD) teria uma percepção militar, embora fosse criado como instância de poder civil. Além do mais, o fato de o EMFA ser um órgão burocrático e com poderes inferiores aos dos ministérios da Marinha, do Exército e da Aeronáutica sinalizava para os seus futuros limites.

O projeto pouco avançou durante os quatro primeiros anos do mandato de FHC, a ponto de o Presidente ter mudado as regras de tempo de permanência no comando do EMFA para permitir que o General Leonel continuasse à sua frente. Até então somente Oficial-General da ativa poderia ocupar esse cargo. Com tempo de ir para a reserva, FHC garantiu a permanência do General Leonel à frente do EMFA para que ele terminasse o esboço do novo Ministério da Defesa. Feito isso, como prêmio o General Leonel ganhou o posto de observador militar brasileiro na Organização das Nações Unidas (ONU) em Nova Iorque, com salário mensal em torno de US\$ $15 \mathrm{mil}^{4}$.

A tarefa do General Leonel foi suavizada devido a um componente externo: bastou os EUA anunciarem que a Argentina seria seu sócio militar extra-OTAN (Organização do Tratado do Atlântico Norte). Imediatamente surgiu a declaração, no dia 17 de agosto de 1997, do Presidente Carlos Menem, de que o lugar dos países latino-americanos no Conselho de Segurança da ONU deveria ser rotativo e não fixo para o Brasil, como desejava a diplomacia verde-amarela, para que o tema do Ministério da Defesa voltasse às páginas dos jornais.

A ocasião escolhida por FHC foi a reunião do

com vistas à criação do Ministério das Forças Armadas. A idéia foi torpedeava pela rivalidade entre as três Forças e afundou.

4 Existe similar posto de observador militar em Genebra. Esses cargos foram criados pelo Presidente José Sarney para agradar militares que cooperaram com a sua subida ao poder. Embora FHC tenha patrocinado uma reforma administrativa do Estado, tais cargos foram mantidos. Lula, até o momento, segue a mesma trilha de Sarney, Collor, Itamar Franco e FHC.
Grupo do Rio ${ }^{5}$ em Assunção. No dia 24 de agosto de 1997, o Presidente brasileiro anunciou a criação do Ministério da Defesa. Foi uma clara manobra política para favorecer a candidatura do Brasil a um assento no Conselho de Segurança da ONU, já que seria difícil explicar ao mundo como um país com vaga nesse Conselho aspira a decidir sobre questões de segurança internacional tendo quatro ministros militares respondendo pela pasta da Defesa. Pela gênese de sua criação, percebiase que o MD não foi primordialmente criado para ajudar a submeter os militares ao controle democrático civil, mas com fins instrumentais. Os fatos posteriores confirmaram a suspeita.

O Projeto de Emenda Constitucional (PEC) n. 498/97 propôs a criação do Ministério da Defesa. Essa PEC, todavia, também procurou agradar os militares. O relator da PEC, Deputado Federal Benito Gama, da aliança governista ${ }^{6}$, afirmou que o novo Ministro da Defesa civil seria uma espécie de "rainha da Inglaterra", ou seja, reina mas não governa (ZAVERUCHA, 2000, p. 52). Em outras palavras, o Ministro da Defesa seria peça decorativa, pois o poder, de fato, continuaria nas mãos dos militares (LACERDA \& CARVALHO, 1998). Caberia ao Ministro da Defesa limitadas atribuições como a de centralizar o orçamento das Forças Armadas, comprar armas e redigir a política de defesa do Brasil.

A fragilidade institucional do novo Ministro da defesa é evidente. No modelo norte-americano, a posição institucional do Ministro da Defesa é fortalecida. Esse modelo foi logo descartado pelos militares brasileiros sob a alegação de termos peculiaridades distintas. $O$ fato é que o Ministério da Defesa do Brasil não possui um Estado-Maior Geral forte que comande Marinha, Exército e Aeronáutica. O Ministro da Defesa, lembra Lopes (2001), "lida diretamente com os comandantes de

5 O Mecanismo Permanente de Consulta e Concertação Política - Grupo do Rio (GRIO) - foi criado em 1986, no Rio de Janeiro. Dele fazem parte Argentina, Bolívia, Brasil, Chile, Colômbia, Equador, México, Paraguai, Peru, Venezuela, Uruguai e um representante da Comunidade do Caribe (Caricom). O Grupo do Rio tem agido na contenção de processos que colocam em risco a ordem democrática.

6 Na época, Gama pertencia ao Partido da Frente Liberal (PFL) do estado da Bahia. Posteriormente, transferiu-se para o Partido do Movimento Democrático Brasileiro (PMDB). 
cada Força. Ao Estado-Maior Geral denominado no Brasil de Estado-Maior da Defesa, cabe a função de assessoria de cunho especificamente militar. Também é preciso ressaltar: apesar dessa linha direta com os comandantes militares [o Ministro da Defesa] não ordena operações. No modelo americano, o Secretário da Defesa controla pessoalmente os chamados Comandos de Área, completamente operacionais. Cada Força tem subsecretário basicamente para tratar de assuntos administrativos".

Outra prova da fragilidade institucional do Ministro da Defesa é que os comandantes militares do Exército, da Marinha e da Aeronáutica deixaram de ser politicamente ministros de Estado, mas mantiveram o status jurídico de Ministro. Ou seja, cabe ao Supremo Tribunal Federal processar e julgar as infrações penais comuns e crimes de responsabilidade tanto dos ministros de Estado como dos comandantes militares.

Os comandantes militares são, também, membros natos do Conselho de Defesa Nacional e da Câmara de Relações Exteriores e Defesa Nacional do Conselho de Governo. Destarte, o Ministro da Defesa é o único Ministro de Estado a carregar a tiracolo seus subordinados para as reuniões do referido Conselho e da mencionada Câmara. Tais comandantes também possuem a prerrogativa de, juntamente com o Ministro da Defesa, indicar ao Presidente da República os nomes para a promoção de oficiais-generais. A lista, portanto, será feita por três militares e um civil. Fica o registro, pois na prática isso pouco importa. Desde 1985 os presidentes da República acataram integralmente os nomes propostos pela cúpula militar para promoção.

FHC quis indicar o diplomata Ronaldo Sardenberg para ser o novo Ministro da Defesa. Diante da histórica rivalidade entre o Itamarati e as Forças Armadas, o Presidente cedeu às pressões castrenses e foi em busca de alternativa. A escolha não poderia ter sido pior. Nomeou o exlíder do governo no Senado Federal, Senador Élcio Álvares, que acabara de ser derrotado nas eleições em seu estado, Espírito Santo, e era pessoa sem qualquer experiência profissional na área ${ }^{7}$. Na interpretação dos militares, FHC usou a pasta

7 Álvares teve que se desfiliar de seu partido político, o PFL, para assumir o Ministério. para empregar um político derrotado e dar um prêmio de consolação ao seu ex-líder, em vez de fortalecer o novo Ministério.

Além disso, Álvares assumiu na qualidade de Ministro Extraordinário da Defesa; apenas seis meses depois, em 10 de junho de 1999, foi empossado como Ministro de Estado da Defesa. Nesse momento, o Estado-Maior das Forças Armadas foi extinto e os ministérios da Marinha, do Exército e da Aeronáutica, transformados em Comandos. Portanto, o Ministro nasceu antes do Ministério ${ }^{8}$. Em um intervalo de aproximadamente seis meses, nessa área o Brasil conviveu com cinco ministérios: o da Defesa, Marinha, Exercito, Aeronáutica e EMFA. Enquanto essa situação perdurou, Álvares ficou na incômoda situação de, ao assinar documentos oficiais, ter de pedir a assinatura de seus subordinados, comandantes militares (HOLOFOTES, 1999). Álvares era o homem na hora e no lugar errados.

Álvares procurou conquistar a simpatia dos militares; chegou a ponto de interceder politicamente no Senado, para que a indicação do General José Luís Lopes da Silva ao cargo de Ministro do Superior Tribunal Militar (STM) fosse aprovada. O mencionado General comandou as tropas que invadiram a Companhia Siderúrgica Nacional, em 1988, resultando na morte de três grevistas. Álvares alegou aos senadores que uma derrota na nomeação de Lopes deixaria o Exército em uma situação delicada (LIMA, 1999). Quem deveria ser réu tornou-se juiz.

Na cerimônia de posse do novo Ministro, todavia, já se podia pressentir o que ocorreria no futuro. "Vamos embora que a festa é do Senador [Álvares]”, disse o Brigadeiro Walter Brauer, Comandante da Aeronáutica, quando as autoridades faziam fila para os cumprimentos. Aliás, nenhum comandante das três Forças cumprimentou o novo Ministro da Defesa (ÉLCIO ÁLVARES $X$ FORÇAS ARMADAS, 1999). Um deles, o Almirante Mauro Pereira, não compareceu alegando problemas pessoais (FRANÇA, 1999).

8 Álvares despachava em uma pequena sala no quarto andar do prédio do EMFA e foi, depois, transferido para uma outra pequena sala. Ele só ocupou o gabinete do Ministro-chefe do Estado Maior das Forças Armadas quando o Diário Oficial da União publicou sua nomeação como Ministro efetivo da Defesa e não mais extraordinário. 


\section{A SAÍDA DE ÁLVARES}

A crise que se delineava tomou novo fôlego com a decisão de Álvares de dar à sua assessora e amiga, Solange Antunes Resende, o poder de comandar reuniões com generais, almirantes e brigadeiros. A irritação dos "quatro-estrelas" aumentou quando a revista Istoé noticiou que Resende e seu irmão, Dório Antunes, sócio de Álvares em um escritório de advocacia, teriam defendido clientes envolvidos com o narcotráfico (MEIRELES, 1999).

A seguir nova denúncia nesse mesmo sentido foi feita pela Comissão Parlamentar de Inquérito (CPI) do Narcotráfico. A CPI decidiu quebrar os sigilos bancário, fiscal e telefônico de Resende e seu irmão. Foi o mote para a indisciplina militar: o Brigadeiro Brauer declarou que não daria conselhos ao seu superior por nunca ter passado por tal situação e lembrou que "a vida pública tem que ser bastante ilibada, transparente, que não deixe dúvidas” (MARTINS, 1999). Ou seja, Álvares e Resende deveriam deixar seus cargos, na visão do Brigadeiro. Claro ato de indisciplina militar.

FHC resolveu intervir. Demitiu o Brigadeiro Brauer e pediu o cargo de Resende. Álvares, por sua vez, ganhou uma sobrevida. A demissão de Brauer aumentou a insatisfação na Aeronáutica - tanto é que FHC escolheu como substituto o Brigadeiro Carlos de Almeida Baptista, que atuava como Juiz no Superior Tribunal Militar. Ou seja, o Presidente não encontrou um oficial de confiança entre os que estavam em plena atividade.

Durante a cerimônia de posse de Baptista o clima foi de constrangimento. Brauer foi muito aplaudido após finalizar seu discurso de despedida eivada de críticas ao governo ${ }^{9}$. Afora essa manifestação, o Comando da Aeronáutica providenciou um desfile de tropas, além de manobra aérea de que participaram o "Sucatão"10 (cercado por

\footnotetext{
9 Uma delas foi contra o uso pouco parcimonioso de jatos da Força Aérea Brasileira (FAB), para fins particulares, por parte de alguns ministros de Estado. Vários desses ministros usaram aviões da FAB para conhecerem a paradisíaca ilha de Fernando de Noronha, em Pernambuco. Brauer revelou à imprensa, no início de 1999, a lista com os nomes dos ministros, irritando o Palácio do Planalto.
}

10 Apelido do avião presidencial (um boeing 707), já bastante antigo e que FHC julgava inseguro. Brauer concorda- quatro jatos F-5 simulando reabastecimento); quatro mirages; oito AM-X, um boeing 737; um learjet e dois HS (AZEREDO, 1999). O alinhamento das aeronaves simulava a falta de um companheiro de vôo, em uma referência à ausência do Brigadeiro Brauer (LEALI, 1999).

Paralelamente, o Comando da Aeronáutica emitiu uma nota de apoio a Brauer, de que constavam as assinaturas de oito tenentes-brigadeiros. A nota, entre outras coisas, dizia que Brauer "deixa o Comando da Aeronáutica gozando do mais elevado respeito, admiração e confiança junto a seus pares do Alto Comando [...] [e que] o Alto Comando da Aeronáutica reafirma que os valores morais e éticos que sempre nortearam nossa instituição serão preservados a qualquer custo, sob a égide da hierarquia e da disciplina"11.

Em seguida foi a vez do Clube da Aeronáutica organizar almoço de desagravo a Brauer. Na ocasião, com a presença majoritária de oficiais da reserva, as críticas contra o Presidente da República subiram de intensidade. Em países detentores de uma sólida cultura cívica, militares, uma vez fora das fileiras, comportam-se como civis, em especial na vida política do país. No Brasil, a patente ainda procura impor-se à vida civil. O militar da reserva vê-se como porta-voz do estamento militar - e o que porta-voz faz é falar.

O Presidente do Clube, Brigadeiro Ércio Braga, em tom sedicioso, afirmou que "não se pode falar na legalidade de um governo que, por sua ação, se torna ilegítimo, dado que o compromisso do militar é com a nação, não com o governo" (ALVES, 1999; sem itálicos no original). O Brigadeiro Ivan Frota, por sua vez, defendeu o impedimento de FHC. Já o Deputado Federal e Capitão do Exército Jair Bolsonaro propôs que o Brasil seguisse o modelo de Hugo Chávez, ou seja, um militar na Presidência da República (MILITARES DÃO SINAL AMARELO, 1999). Em relação a FHC, Bolsonaro teve a ousadia de dizer: "Ele, para mim,

va com a alegação de ser o avião antigo na idade, mas discordava no que se referia à quantidade de horas voadas. $\mathrm{O}$ vôo do "Sucatão" foi uma forma de o Comando da Aeronáutica mostrar que as queixas de FHC eram exageradas.

11 Segundo um ex-Ministro da Defesa, a Aeronáutica teria sondado o Exército e a Marinha no sentido de promover um golpe de Estado. A proposta não contou com o apoio das duas outras forças. 
tinha de ser fuzilado" (DISCURSOS PEDEM IMPEACHMENT, 1999).

A ira da Aeronáutica para com sua pessoa era, segundo Álvares, devido a outras razões. Ele havia descoberto que a Aeronáutica requisitara 27 mil passagens às companhias aéreas para trabalho de fiscalização da aviação civil, o que considerou um exagero. Afora isso, Álvares trabalhava pela criação de uma Agência Nacional de Aviação Civil, o que retiraria poder da Aeronáutica. "Muitos brigadeiros aposentados que aplaudiram o discurso do Bräuer no Clube da Aeronáutica ocupam cargos na Infraero, no DAC [Departamento de Aviação Civil] ou em companhias aéreas. Serão atingidos pelas mudanças que estou fazendo", finalizou Álvares (2000). O fato é que o DAC continuou até o final do governo FHC sob controle da Aeronáutica e a Agência Nacional de Aviação Civil não decolou. Por sua vez, após 17 anos de comando militar, a Infraero passou a ser dirigida por um civil (FRANÇA, 2000).

Receoso de que a rebeldia dos militares da reserva contaminasse os da ativa, Álvares procurou rapidamente fazer um afago na Aeronáutica. Conseguiu com o Ministro interino da Fazenda, Amaury Bier, a liberação dos recursos restantes retidos do Ministério da Defesa. A verba de R\$ 51 milhões foi destinada ao custeio do Sistema Integrado de Vigilância da Amazônia (Sivam) (PLANALTO ADOTA ESTRATÉGIA, 1999).

A autoridade de Álvares seria, mais uma vez, tisnada - no último dia do ano. Durante o revéillon realizado no Forte de Copacabana com a presença do Presidente da República, houve um desagradável incidente. Pouco antes do início da queima de fogos na praia de Copacabana, vento e chuva fortes danificaram a estrutura do galpão da festa organizada para FHC. Os fotógrafos Fernando Bizerra e Sheila Chaves, que estavam credenciados, registraram o ocorrido. Irritados, soldados do Exército agrediram os profissionais.

O incidente ocorreu em uma sexta-feira. Somente na segunda-feira à tarde é que foi publicada uma nota oficial do Exército corroborada pelo Ministério da Defesa anunciando a abertura de um Inquérito Policial Militar - e isso devido à intervenção pessoal de FHC, pois a intenção original do Exército era abrir apenas uma sindicância. Em vez de Álvares sair em defesa do Presidente ocorreu o contrário. A impressão que ficou foi a de que Álvares sentiu-se intimidado em tomar uma decisão enérgica que desagradasse os militares.

Isso sem falar na ausência de Álvares no revéillon, embora assinasse o convite oficial para a festa. Álvares saiu do episódio mais fraco do que quando entrou (KRAMER, 2000). A situação era delicada pois, segundo o próprio Álvares, “o Ministério da Defesa é o fiador da democracia no Brasil" (ÁLVARES, 2000). Álvares cairia alguns dias depois.

\section{UM NOVO MINISTRO}

Com a queda de Álvares, o novo Ministro foi Geraldo Quintão, que até então era o Advogado Geral da União. Uma de suas funções era a de proteger o patrimônio do Estado. No entanto pesava sobre ele uma investigação sobre vôos particulares financiado pelo mesmo Estado a que devia proteção. Um levantamento feito pela Aeronáutica revelou que entre janeiro de 1995 e dezembro de 1998 Quintão teria usado aviões da FAB para viajar nos fins de semana para São Paulo, onde mora sua esposa. Teriam sido 32 viagens financiadas pelos impostos dos contribuintes (LEALI, 2000).

O inquérito foi aberto pelo Procurador da República, Guilherme Schelb, em 11 de maio de 1999, estando nele incluídos, afora Quintão, outros ministros de Estado. Ao tornar-se pública a investigação, Quintão, irritado, acusou o Ministério Público de exibicionismo (QUINTÃO: MINISTÉRIO PÚBLICO, 2000). Segundo ele, tinha o direito de uso de transporte aéreo para deslocar-se à sua residência (QUINTÃO, 2003). Também alegou que viaja em aviões da FAB desde 1993, quando servia ao governo Itamar Franco e nunca o Ministério Público havia-o repreendido. Schelb, por sua vez, rebateu as críticas de Quintão com um argumento sociológico: "é um ranço do nosso passado colonial ter carroça para carregar alguém especial” (PROMOTOR REBATE CRÍTICA, 2000). As viagens não foram consideradas ilegais.

Quintão assumiu logo anunciando ações que agradaram em cheio os militares: estudo para aumento de soldos; incremento de verbas para a modernização das Forças Armadas e defesa de um sistema previdenciário diferenciado do civil (AZEREDO, 2000).

A verba prometida não foi entregue e isso gerou insatisfação nas hostes castrenses com o Pre- 
sidente da República e, por tabela, com o Ministro da Defesa. Em outubro de 2000, FHC resolveu demitir o Comandante do Exército, General Gleuber Vieira, por sua declaração criticando a falta de verbas. Enfrentou, então, a mais séria crise militar de sua gestão. A decisão presidencial chegou aos quartéis. Imediatamente, 155 generais de todo o país reuniram-se em Brasília, sem a presença do Ministro da Defesa, Geraldo Quintão, em ato de desagravo ${ }^{12}$. FHC entendeu a mensagem e logo escalou o General Alberto Cardoso, chefe do Gabinete de Segurança Institucional para anunciar que Gleuber não seria mais demitido. Em troca os militares não fariam nenhuma manifestação pública. Estes, por sua vez, exigiram a edição de uma Medida Provisória concedendo reajuste salarial - no que foram atendidos.

Mesmo assim, os militares mandaram um novo recado a FHC. Durante o almoço de 12 de dezembro de 2000, os fardados não aplaudiram o Presidente ao término do discurso em que anunciava o aumento salarial. Em compensação, o discurso do anfitrião, General Gleuber Vieira, foi entusiasticamente aplaudido por quase um minuto (FRANÇA \& NAHASS, 2000). O Ministro da Defesa também experimentou uma pitada da insatisfação de seus, teoricamente, subordinados. A assessoria de Quintão solicitou ao Exército uma sala para entrevista com a imprensa e três máquinas de fotocópias para distribuição das novas tabelas de aumento. Embora o Clube do Exército possua vários auditórios e escritórios, a sala solicitada não foi cedida sob a alegação de não haver espaço disponível no Clube. O mesmo aconteceu com as fotocopiadoras sob a excusa de estarem quebradas. Resultado: Quintão imprimindo em um tablado no meio do salão de baile teve de atender aos jornalistas em pé (ibidem).

O Ministro Quintão entendeu o recado e mostrou-se tão preocupado em agradar os militares que foi capaz de esquecer, momentaneamente, sua formação jurídica. Em março de 2001, em visita ao estado amazônico de Roraima, Quintão entusiasmou-se. Ante uma platéia de militares incorporou o discurso dos mesmos dos anos 1970 contrário à demarcação de terras indígenas contínu-

12 Quintão negou tanto o desejo de FHC de demitir o General Gleuber quanto a mencionada reação do generalato (QUINTÃO, 2003). as. Aproveitou para desancar o ex-Presidente Fernando Collor, responsável pela demarcação da área ianomâmi. Segundo Quintão, “uma demarcação contínua onde não pode ser contínua, que foi feita por incompetência ou por necessidade de um Presidente da República de aparecer bem lá fora porque estava caindo aqui, e serviu de péssimo exemplo" (RODRIGUES, 2001). Foi aplaudido ao estimular a violação de artigo constitucional. Afinal, o que Collor fez nada mais foi do que cumprir o estipulado pela Constituição Federal de 1988, gostasse ou não o Ministro Quintão.

A questão orçamentária voltaria a incomodar Quintão. Em crise econômica e em nome da governabilidade, o governo federal bloqueou recursos destinados ao Exército. Isso fez que, dentre outras medidas, fossem adiadas a incorporação de novos recrutas; a liberação precoce dos já incorporados; suspensão de auxílio-transporte e auxílio pré-escolar para militares etc. (EXÉRCITO CORTA, 2002). Em nota oficial criticando o governo e à revelia do Ministro Quintão, o General Gleuber afirmou, entre outras coisas, que "a alta administração do Exército avaliou que tal quadro atingiu o limite das medidas paliativas, não restando outra alternativa senão a adoção de soluções drásticas que comprometem a disponibilidade futura e a operacionalidade da Força Terrestre" 13 .

Quintão, todavia, soube ser generoso com um outro Presidente da República. FHC criou, em julho de 2002, a condecoração de Grão-Mestre da Ordem do Mérito da Defesa. Dois meses depois, Quintão decidiu condecorar apenas FHC com a Ordem que ele próprio criara. A honraria, segundo Quintão, deveu-se aos "relevantes serviços prestados às Forças Armadas” (KRIEGER, 2002). O Presidente retribuiu a homenagem com uma singela declaração sobre a democracia brasileira, o Ministério da Defesa e as Forças Armadas: “Quero agradecer o espírito de compreensão, de colaboração do Ministério da Defesa e das várias forças singulares, que nunca faltaram ao país, ao governo e nunca faltaram a mim, pessoalmente. Se há um corpo do Estado brasileiro que, dentro das regras da democracia, tem funcionado de uma maneira absolutamente impecável, é o Ministério da Defesa” (JUNGBLUT, 2002).

13 A íntegra da nota pode ser lida da edição do Jornal do Brasil de 12 de julho de 2002. 
Impecabilidade deve ser sinônimo de desimportância. Em maio de 2000, a justiça argentina enviou pedido de informações, por meio do Supremo Tribunal Federal, sobre a existência da Operação Condor no Brasil ${ }^{14}$. Quintão recebeu a solicitação e afirmou que o governo abriria os arquivos dos órgãos de inteligência militares para responder ao pedido da justiça argentina (ARQUIVOS DO REGIME MILITAR, 2000). Contudo, os arquivos continuaram fechados - até hoje.

Em outra ocasião, em outubro de 2001, Quintão não foi convidado para participar da decisão que levou o Brasil a invocar o Tratado Interamericano de Assistência Recíproca (TIAR) (CRUVINEL, 2001). Essa decisão foi uma iniciativa do então Ministro da Relações Exteriores, Celso Lafer, de implementar no plano regional a mobilização internacional de apoio aos EUA, após os ataques de 11 de setembro de 2001. Quintão também não opinou sobre a abertura do escritório do Serviço Secreto dos EUA em São Paulo (ibidem). Ou seja, o próprio governo contribuiu para enfraquecer o Ministro Quintão.

Mesmo assim, Quintão adotou um low profile. Esse mineiro de trato afável, além de não reclamar, aceitou que mais da metade dos cargos do Ministério da Defesa fossem indicados pelos militares e que no organograma oficial seu cargo aparecesse ao lado, em vez de acima, dos comandantes militares ${ }^{15}$. Quintão cumpriu a contento o papel que lhe foi confiado por FHC: ser discreto para não criar atritos com os militares. Deixou o cargo com ótimo relacionamento com os comandantes militares.

\section{UM DIPLOMATA COMO MINISTRO DA DEFESA}

O Presidente Lula, ao contrário de FHC, conseguiu nomear um diplomata para conduzir o Ministério da Defesa: José Viegas, mas fê-lo pagando um preço elevado. Subvertendo a hierarquia,

\footnotetext{
14 Operação de colaboração entre os governos militares nas décadas de 1970 e 1980 de combate aos opositores políticos. Novas informações sobre essa operação foram descobertas em arquivos depositados no Paraguai.

15 Além disso, na Esplanada dos Ministérios, em Brasília, aparecem nos prédios os dizeres: "Ministério da Defesa Exército Brasileiro, Marinha Brasileira e Aeronáutica Brasileira”, ao invés de "Comando do Exército, Comando da Marinha e Comando da Aeronáutica”.
}

conceito tão caro aos militares, Lula indagou aos três comandantes militares do governo FHC se aceitavam o nome de Viegas. Com o sinal positivo dos comandantes, Lula confirmou o nome do novo Ministro. Desse modo, Viegas começou a cair antes mesmo de assumir, ao tornar-se refém das Forças Armadas. Teria que se contentar em ser, como seus antecessores, uma "rainha da Inglaterra", ou seja, um despachante dos interesses militares, algo improvável, dada a rivalidade corporativa entre o Itamarati e as Forças Armadas.

Viegas não entendeu ou não levou a sério as regras do jogo. Tomou medidas que desagradaram, particularmente, o Comandante do Exército, General Francisco Roberto de Albuquerque. O Ministro criticou a falta de empenho do Exército, ao contrário da Marinha e Aeronáutica, na busca de corpos de desaparecidos da Guerrilha do Araguaia; levou adiante um projeto de reengenharia administrativa (aí incluída a reestruturação curricular e de comando da Escola Superior de Guerra - ESG ${ }^{16}$ ); comportou-se como membro do governo ante os quartéis ao aceitar a decisão da área econômica em não dar aumento salarial para os militares e solicitou que os comandantes militares não fizessem declarações públicas em favor de tal aumento, bem como exigiu que o Exército se adequasse aos termos do Estatuto do Desarmamento patrocinado pelo governo.

O desgaste no relacionamento administrativo entre Viegas e os militares degenerou em aberta indisciplina. Embora já exista uma Assessoria Parlamentar do Ministério da Defesa ${ }^{17}$, o General

16 Esse fato irritou o General Oswaldo Muniz Oliva, pai do Senador Aloízio Mercadante, e o ex-Ministro Leônidas Pires Gonçalves, que foram, com José Sarney, artífices do aceite do nome de Lula ante a caserna. Achavam que a ESG deveria ser dirigida por um general quatro-estrelas, em vez de um três-estrelas, como é atualmente. Por sua vez, Viegas trabalhava com a possibilidade de a ESG poder ser dirigida até mesmo por um civil. O General-de-Brigada José Luiz Halley, encarregado pelo Ministro da Defesa de levar adiante o projeto de modernização da ESG, teve sua promoção indeferida pelo Exército e foi para a reserva.

17 Afora a Assessoria Parlamentar do Exército (4 membros) no Congresso Nacional, funcionam a Assessoria da Marinha (3 membros) e da Aeronáutica (3 membros). Além disso, o Exército possui assessorias parlamentares em dez estados da federação: Rio Grande do Sul, Santa Catarina, Paraná, São Paulo, Rio de Janeiro, Amazonas, Mato Grosso do Sul, Bahia, Ceará e Pernambuco (LEGISLATIVO É ACOMPANHADO, 2002). 
Albuquerque indicou um general para substituir um coronel nessa assessoria. Esse foi um claro desvio de função do General, além de sinalizar sua indisposição em extinguir tal assessoria; o Comandante do Exército freqüentou solenidades com farda militar inadequada para a ocasião, em aberta provocação (KRAMER, 2004); além disso, não enviou uma lista tríplice com o nome de generais a serem escolhidos pelo Ministro para irem ao Haiti. Pelo contrário, Albuquerque nomeou autonomamente tanto o general que comandava a força de paz da ONU como o que lidera os militares brasileiros nessa força.

Atos de indisciplinas desse quilate passaram em branco, em uma clara demonstração de fraqueza de Viegas. Obviamente, mais estaria por vir. O estopim de nova crise foi a publicação por parte do Correio Braziliense de fotos supostamente do jornalista Vladimir Herzog sendo submetido à tortura antes de ser morto em prisão militar ${ }^{18}$. Herzog foi assassinado em 1975, em uma onda de prisões contra integrantes do Partido Comunista Brasileiro (PCB). A versão oficial de suicídio não foi aceita pelo então Presidente Ernesto Geisel, que mandou demitir o Comandante do II Exército, General Ednardo D’Ávilla Mello.

Em vez de tratar as fotos como um fato histórico e nada mais, inesperadamente o Exército soltou uma nota que foi considerada ofensiva pelo Presidente Lula. A nota afirma que o Exército não mudou suas convicções sobre o acontecido naquele período histórico e que "considera ação pequena reavivar revanchismos ou estimular discussões estéreis sobre conjunturas passadas, que a nada conduzem"19.

O Exército, além de falar em nome das Forças Armadas, sem o consentimento da Marinha e da Aeronáutica, desautorizou o Ministério da Defesa. Enquanto Viegas afirmara que os documentos da Guerrilha do Araguaia haviam sido incinerados, a nota disse que não apenas esses documentos foram destruídos mas que "os registros operacionais e da atividade de inteligência da época [do regime militar]" também o foram.

\footnotetext{
18 Posteriormente se comprovou que as fotos não eram de Herzog.

19 Para a íntegra da nota, cf. O Globo de 19 de outubro de 2004.
}

Viegas exigiu por escrito que o General Albuquerque revisse a nota por que a considerava inadmissível. O Ministro não aceitou, por duas vezes, os termos da nova nota que mudou o tom mas não a substância da nota anterior. Informado por fax sobre as duas notas, o Presidente Lula, que se encontrava fora de Brasília, marcou um encontro com Viegas e Albuquerque na Base Aérea de Brasília, onde "precisou fazer, ele mesmo, um remendo de última hora no texto, para tornálo um pouco menos fugidio" (FREITAS, 2004). Ficou acertado entre os três que a nova versão seria entregue, primeiramente, ao Ministro da Defesa.

O Coronel Oliva, em nome do General Albuquerque, ignorou Viegas e entregou pessoalmente a nova nota ao Presidente Lula. O Presidente, então, lembrou que antes Viegas deveria ver a nova versão e só então o Coronel Oliva foi encontrar-se com Viegas.

Em vez de demitir o General Albuquerque por indisciplina, Lula tratou-o com luva de pelica e considerou o incidente como sendo fruto da inabilidade política de Viegas. Lula mostrou-se receoso de exercer plenamente sua condição de comandante-em-chefe das Forças Armadas, conforme estipula o artigo 142 da Constituição Federal, e não demitiu o Comandante do Exército. Com medo de exercer sua autoridade, fragilizou-se (CORRÊA, 2004).

Embora lamentasse a morte de Herzog, a substância da primeira nota não foi alterada: os arquivos continuariam fechados aos civis. O General Albuquerque tentou justificar o teor da primeira nota, publicada pelo Centro de Comunicação Social do Exército, como fruto da "ausência de uma discussão interna mais profunda sobre o tema". Até o momento, aguarda-se uma nova nota com o resultado dessa discussão interna mais profunda.

Demissionário, Viegas publicou a nota mais dura já escrita por um Ministro de Estado, desde 1985, em relação aos militares. Segundo o exMinistro, "a nota escrita em nome do Exército Brasileiro que, usando linguagem totalmente inadequada, buscava justificar lamentáveis episódios do passado e dava a impressão de que o Exército, ou, mais apropriadamente, os que redigiram a nota e autorizaram a sua publicação, vivem ainda o clima dos anos setenta, que todos queremos supe- 
rar. É incrível que a nota original se refira, no século 21, a 'movimento subversivo' e a 'Movimento Comunista Internacional'. É inaceitável que a nota use incorretamente o nome do Ministério da Defesa em uma tentativa de negar ou justificar mortes como a de Vladimir Herzog. É também inaceitável, a meu ver, que se apresente o Exército como uma instituição que não precise efetuar 'qualquer mudança de posicionamento e de convicções em relação ao que aconteceu naquele período histórico"” (VIEGAS FILHO, 2004).

Em substituição a Viegas, Lula indicou o vicePresidente da República, José de Alencar, para Ministro da Defesa. Como terá dificuldade em substituí-lo pois é o eventual comandante-em-chefe das Forças Armadas na ausência do Presidente da República, é de esperar-se que Alencar cumpra os termos do pacto da transição: os militares aceitam a democracia eleitoral em troca da manutenção de enclaves autoritários dentro do aparato de Estado. Um desses domínios reservados é a posse da chave dos arquivos da repressão militar.

Merece registro a reação de alguns parlamentares do Partido dos Trabalhadores (PT). O líder do governo na Câmara dos Deputados, Professor Luizinho, do PT de São Paulo, disse que a atitude de Lula "mostra o apreço do Presidente pelas Forças Armadas” (PRESIDENTE FAZ NOMEAÇÃO, 2004). Na mesma linha, o líder do governo no Senado Federal, Aloízio Mercadante, disse que “o Presidente dá uma demonstração do prestígio das Forças Armadas" (ibidem). Mercadante, juntamente com o seu pai, o General da reserva Oswaldo Muniz Oliva, e seu irmão, o Coronel Oswaldo Muniz Oliva, Secretário-Executivo do Núcleo de Assuntos Estratégicos da Secretaria de Comunicação do governo federal, ajudaram a manter intacto o General Albuquerque (MENEZES, 2004).

O Coronel Oliva, lotado no Gabinete do Comandante do Exército, já havia sido designado para o cargo de Adjunto do Adido do Exército junto à Embaixada do Brasil nos Estados Unidos, cumulativamente com o cargo de Chefe da Comissão do Exército Brasileiro em Washington (CEBW), quando o então Ministro da Secretaria de Comunicação, Luiz Gushiken, em setembro de 2004, requisitou-o para o Núcleo de Assuntos Estratégicos da Presidência da República (BRASIL. MINISTÉRIO DA DEFESA. EXÉRCITO BRASILEIRO, 2004). Era um modo de o Coronel Oliva dialogar, em nome do comandante-em-chefe das
Forças Armadas, Presidente Lula, com o General Albuquerque, que vivia às turras com o Ministro Viegas. Ou seja, a via pessoal por cima da atitude institucional.

Tal qual uma rainha da Inglaterra, Alencar, ao assumir, foi logo se submetendo à vontade dos militares ao dizer: "Minha visão é daqui para a frente. Não tenho nada com o passado" (CARVALHO \& DAMÉ, 2004). Em seguida, anunciou a manutenção do indisciplinado General Albuquerque à frente do Comando do Exército, ante o silêncio absoluto do Congresso Nacional. Fatos como esses confirmam ser o militarismo um fenômeno amplo, regularizado e socialmente aceito no Brasil: prefere-se estabilidade política ao aprofundamento da democracia brasileira.

\section{O MINISTÉRIO DA DEFESA E AS COMIS- SÕES MILITARES}

As Forças Armadas mantêm no exterior 248 pessoas ${ }^{20}$ com a função exclusiva de comprar armamento, equipamentos e até munição para os militares. Essa "tropa" custa ao governo R\$ 16 milhões por ano (PATURY, 1999) e é cinco vezes maior que a Força de Paz no Timor Leste (50 militares).

Em 1999, a Marinha inaugurou uma nova sede em Washington, mais precisamente no MacArthur Boulevard, um dos endereços mais caros da capital norte-americana. Foram gastos US\$ 2 milhões na compra do prédio e mais US\$ $800 \mathrm{mil}$ com reformas (PINTO, 2002). A mudança foi feita para abrigar uma outra distorção: a presença de 11 militares e 29 civis na Comissão Naval na cidade. Em Londres, a Marinha mantém 11 militares e 34 civis $^{21}$. As despesas com este pessoal custaram ao contribuinte brasileiro, em 2001, US\$ 7,2 milhões (ibidem). Nessa Comissão Naval, a faxineira foi promovida a telefonista e recebe um salário mensal de US\$ 5 500,00, maior que o do Presidente da República (PATURY, 1999).

Há ainda uma terceira distorção: a salarial. Em 2002, o salário de um General-de-Brigada brasileiro nos Estados Unidos chegava a US\$ $14 \mathrm{mil}$ (R\$ 34 mil), enquanto no Brasil esse mesmo General perceberia R\$ 6 mil (PINTO, 2002). Isso

\footnotetext{
20 Funcionários civis, militares e estrangeiros.

21 O Exército mantém 11 militares e 16 civis em Washington. A Aeronáutica acolhe 7 militares e 45 civis.
} 
contribui para explicar porque o custo da manutenção dos militares no exterior é alto. Para termos uma idéia da disparidade, um recruta percebe o soldo de R $\$ 153$ mensais (MARQUES, 2002) e vários deles, em 2002, foram dispensados por falta de verba (ÉBOLI, 2002). Há uma lei de 1972 que regulamenta a remuneração de funcionários públicos civis e militares no exterior, com o objetivo de protegê-los das flutuações cambiais; essa proteção, todavia, transformou-se em prêmio econômico - para alguns.

Não é uma exclusividade brasileira a existência de comissões militares. Elas têm como função primordial a compra de armamento e munições. O que chama atenção é que apenas Brasil e Argentina possuem um prédio para cada uma das três forças em Washington (PINTO, 2002). Se as três Forças são co-irmãs e devem atuar em conjunto em caso de guerra, o que as impede de trabalharem em um mesmo prédio? Por que se mantêm a mesma estrutura anterior à criação do Ministério da Defesa brasileiro?

O então Deputado Federal Agnelo Queiroz (Partido Comunista do Brasil, eleito pelo Distrito Federal), ao comentar as despesas militares no exterior, sobretudo nas comissões, afirmou: "O que se questiona não é a legalidade, mas a moralidade dos gastos”. O então Presidente da Comissão de Relações Exteriores da Câmara dos Deputados, Hélio Costa (PMDB-MG), foi incisivo: "Estamos diante de um claro privilégio, que não é compatível com a política de austeridade que o governo prega” (PINTO, 2002). Suas críticas não encontraram eco nem no governo federal nem no Congresso Nacional. Não poderia ser de outra forma, pois a reforma administrativa do Estado de Bresser Pereira já deixara intocado o "Estado militar", ignorando o ônus das comissões militares no orçamento da União.

No ano seguinte, Queiroz decidiu requerer uma auditoria ao Tribunal de Contas da União nas comissões de compras do Exército (26 pessoas), Marinha (56) e Aeronáutica (75) em Londres e Washington, perfazendo 179 pessoas. Na embaixada brasileira na capital norte-americana, a mais importante representação diplomática do país no exterior, trabalham 49 pessoas: o contingente militar que o Brasil enviou ao Timor Leste foi de apenas 50 soldados, sob a alegação de dificuldades financeiras.
Convém lembrar que ainda servem no exterior dois observadores militares perante a ONU, em Nova Iorque e Genebra, cada um percebendo o salário mensal de US\$ 15 mil, sem esquecer os militares que servem na Representação do Brasil na Junta Interamericana de Defesa (RBJID), em Washington ${ }^{22}$. Essa situação manteve-se inalterada durante as gestões dos três ministros da Defesa. Não há indícios de que o atual Ministro, José Alencar, opte por alterar essa situação.

\section{CONCLUSÃO: CARRUAGEM DE VIDRO ${ }^{23}$}

"Quando saudei o nosso Ministro da Defesa, Geraldo Quintão, na sua posse, eu disse e cito de novo: jamais cogitei a criação do Ministério da Defesa para reafirmar o comando civil sobre as Forças Armadas, porque isso não era necessário, posto que, através do Presidente da República, esse elo já existe. Na verdade, a questão do Ministério da Defesa era, como ainda é, operacional e estratégica”, afirmou o Presidente Fernando Henrique Cardoso (2000).

Com uma visão tão equivocada como essa - a de que há um comando civil efetivamente estabelecido sobre as Forças Armadas -, não é surpresa constatar-se que os comandantes-chefes do Exército, da Marinha e da Aeronáutica mantêm o poder de fato e, em conseqüência, o Ministro da Defesa torna-se muito mais uma espécie de despachante institucional das Forças Armadas perante o Presidente da República do que um representante do governo perante os quartéis. A saída do Ministro Viegas deixou isso cristalino.

Do ponto de vista operacional, a criação do Ministério da Defesa não apresentou grandes mudanças. As três Forças relacionam-se com o Ministério da Defesa de modo similar ao que se relacionavam com o extinto Estado-Maior das Forças Armadas.

\footnotetext{
22 A RBJID é uma organização militar diretamente subordinada ao Ministério da Defesa. Coordena a participação brasileira no Conselho de Delegados da Junta Interamericana de Defesa, no seu Estado-Maior e no seu Colégio Interamericano de Defesa (CID). Para maiores informações, consultar RBJID (s/d).

23 Para uma visão mais otimista da influência do Ministério da Defesa na natureza das relações civis-militares, ver Castro (2000).
} 
Quintão até que conseguiu realizar, pela primeira vez, uma operação militar conjunta na Amazônia ${ }^{24}$, mas não conseguiu integrar militarmente as três forças singulares e procurou atender corporativamente as demandas por verbas de cada força. Esse é um reflexo da falta de uma clara política militar de defesa do governo e da sua incapacidade de manter-se fiel às suas decisões. $\mathrm{Ou}$ seja, cada Força singular desenvolve suas atividades desvinculadamente das demais. Não se percebe um projeto integrado que vincule a capacidade bélica desejada ou possível com os recursos orçamentários pertinentes.

O fato é que o Exército continua organizado para lutar uma guerra convencional de remota possibilidade. Isso pode ser constatado no Plano FT-9025, publicado em 1990, para ser implementado até 2015. A Marinha, por sua vez, sedia no estado do Rio de Janeiro o I Comando Naval e outros quatros comandos (Fuzileiros, Divisão Anfíbia, Tropa de Reforço e Chefia de Esquadra), fora outros 30 comandos e diretorias (VILLA, 2004). O maior quartel militar da América do Sul é a Vila Militar, no Rio de Janeiro, sem espaço para manobras bélicas de porte - embora a principal ameaça à nossa soberania esteja na região amazônica.

Ainda nos falta um "livro branco de defesa", um livro em que se assinale qual a política de defesa do país; quais os meios para implementá-la; quais as missões encomendadas às Forças Armadas; qual o nível de força que se possui e que nível de força espera-se alcançar no futuro para poder cumprir as missões encomendadas.

Estratégia, doutrina, organização, treinamento e armamento precisam de modernização (DAY, 2003). As Forças Armadas estão inchadas e excessivamente burocratizadas, com generais fazendo funções administrativas e parlamentares que poderiam ser feitas por coronéis. O Brasil tem uma quantidade de generais em relação à tropa maior do que os exércitos dos EUA, da Inglaterra e de Israel, que estão em guerra. O Brasil tem um general para 1258 comandados contra 1430 dos EUA, 1700 da Inglaterra e 9047 de Israel (EXÉR-

\footnotetext{
24 A Operação Tapuru foi realizada entre 20 e 25 de maio de 2002, mobilizando 4 mil homens.

25 Plano de disposição de tropas em combate da Força Terrestre.
}

CITO BRASILEIRO TEM MAIS GENERAL, 2004). O Ministro Viegas tentou fazer uma reforma administrativa, mas encontrou resistências e terminou saindo.

Mesmo com tantos generais, o Exército possui reduzido grau de aprestamento para simples emergência em conflito de baixa intensidade. Como lembra Lopes (2000): "Para que 200 mil homens no Exército se não dispomos nem de $5 \%$ desse efetivo para uma emergência? Ou se não temos transporte para deslocar um mínimo de 3000 militares de um ponto a outro do país? Temos aviões de ataque modernos, mas sem radares e sem peças de reposição. Temos submarinos, mas quase não temos torpedos".

Por exemplo, as pistas militares do país ainda seguem uma concepção da II Guerra Mundial, voltadas para o Atlântico, enquanto a maior ameaça à integridade do território vem da região andina. A única tropa de elite do Exército preparada para pronto-emprego é a Brigada Pára-Quedista sediada no... Rio de Janeiro, a milhares de quilômetros da fronteira onde atua a guerrilha colombiana. Em caso de invasão-surpresa de tais guerrilheiros, deslocar tal brigada seria complicado e demorado, pois não há pistas para aviões a jato próximas da fronteira ${ }^{26}$, além da falta de mobilidade estratégica, i. e., quantidade suficiente de helicópteros e aviões para transferir tropas e equipamentos. É comum a contratação de aviões comerciais para trasladar o equipamento e tropas para exercícios na Amazônia.

Do mesmo modo, é inaceitável a compra de um porta-aviões para defender a costa Atlântica enquanto o efetivo da marinha fluvial, na vastidão da Amazônia, é de apenas 8 navios fluviais e 16 lanchas rápidas (REFORÇO PARA A AMAZÔNIA, 2003) - lembrando que uma das missões da marinha fluvial é garantir melhor apoio logístico aos pelotões fronteiriços do Exército.

O Ministério da Defesa, fazendo o jogo dos militares, contenta-se em aceitar que o Congresso Nacional exerça apenas um controle contábil, ou seja, a mera alocação ou não de dotações sem

\footnotetext{
26 A região fronteiriça da Amazônia brasileira, limítrofe com outros sete países latino-americanos, equivale a aproximadamente $70 \%$ dos quase 16 mil quilômetros de fronteiras nacionais - e é a mais descoberta em termos de segurança.
} 
que as mesmas estejam necessariamente atreladas a estratégias claramente definidas. Sem esse atrelamento, o corte ou aumento de verbas passa a ser rotina administrativa, deixando de adquirir significado político. A falta de latitude política contribui para emperrar a capacidade do Congresso de influir significativamente nos assuntos de defesa nacional.

O poder Executivo também toma medidas que enfraquecem o Ministério da Defesa: por exemplo, FHC retirou de Quintão o controle do Sistema de Proteção da Amazônia (Sipam), que engloba o Sivam e o Projeto Calha Norte, na região amazônica, e entregou-os ao Ministro-chefe da Casa Civil (BOECHAT, 2002).

Lula, por sua vez, indagou aos comandantes militares se estes aceitavam a indicação de Viegas - em uma clara quebra de hierarquia. Afora isso, permitiu sucessivas indisciplinas do Comandante do Exército vis-à-vis o Ministro da Defesa. O Comandante desde o primeiro momento não se manifestou disposto a acatar ordens de Viegas que lhe desagradassem.

Não se pode olvidar que FHC, quatro dias antes de deixar a Presidência da República, assinou o Decreto n. 4 553, no dia 27 de dezembro de 2002, que entraria em vigor 45 dias após sua publicação - portanto, já no governo de Luiz Inácio Lula da Silva. Esse diploma alterou o Decreto n. 2 134, de 24 de janeiro de 1997, relativo à competência das autoridades na classificação dos documentos ultra-secretos. Até então, o parágrafo único do Artigo 16 desse decreto estipulava que a classificação de tais documentos era feita pelos chefes dos poderes Executivo, Legislativo e Judiciário federais. A partir do Decreto n. 4 553, a competência passou a ser do Presidente e vice-Presidente da República; de ministros de Estado e equiparados e dos comandantes da Marinha, do Exército e da Aeronáutica - embora tais comandantes sejam hierarquicamente inferiores ao Ministro da Defesa.

Ora, o Decreto n. 4553 é inconstitucional porque tem prazos de sigilo superiores aos que a Lei n. 8 159, de 1991, determina: até 60 anos. Desde o início do governo Lula, o Conselho Nacional de Arquivos (Conarq) vinha procurando, sem sucesso, alterar esse decreto. Foi preciso que o Ministro José Viegas entrasse em atrito com o Comandante do Exército, dentre outros motivos, por exigir mais empenho na busca dos desaparecidos do Araguaia, para acelerar sua saída do Ministério. Com a crise no seio do governo, a inconstitucionalidade do decreto aflorou nos meios de comunicação.

Ante a repercussão negativa, FHC justificouse. Disse que na pressa dos últimos dias de Presidência assinou o decreto, que lhe foi apresentado pela assessoria do General Alberto Cardoso, sem medir suas conseqüências (FHC CRIOU PRAZO, 2004). Acrescentou não se opor à sua revogação.

Diante disto, o governo Lula resolveu agir. Assinou o Decreto n. 5 301, em 10 de dezembro de 2004, restaurando os prazos determinados pela Lei dos Arquivos e garantiu o acesso ao público dos documentos sigilosos a partir do vencimento dos seus prazos. Esse Decreto também criou a Comissão de Averiguação e Análise de Informações Sigilosas, compostas pelos ministros da Casa Civil, da Justiça, da Defesa e das Relações Exteriores, além do Chefe do Gabinete de Segurança, do Advogado-Geral da União e do Secretário especial de Direitos Humanos da Presidência da República. Todavia, sorrateiramente abriu no Decreto a brecha para que documentos possam ficar eternamente sigilosos. Os papéis caem em um limbo jurídico e de lá sairão somente se essa Comissão, e não a sociedade, assim desejar.

O Ministério da Defesa, com suas limitadas atribuições, reflete o equilíbrio instável nas relações civil-militares existentes no Brasil. Os civis brasileiros podem dizer que, assim como nas democracias maduras, criaram o Ministério da Defesa; os militares aceitam tal situação por almejarem um lugar para o Brasil no Conselho de Segurança da ONU, aumentando a importância do país, e de suas Forças Armadas, no cenário internacional. Afora isso, o arranjo institucional que resultou na criação do Ministério da Defesa torna o Ministro da Defesa muito mais um representante da caserna ante a Presidência da República do que do governo na caserna, não esquecendo que os comandantes das três Forças garantiram o status jurídico de ministros de Estado, bem como presença regimental nas reuniões do Conselho de Defesa Nacional.

Apesar de tudo o que foi relatado, o Ministro Quintão acreditava que o controle civil sobre os militares foi estabelecido. Em palestra proferida em 28 de outubro de 2003, na VI Conferência 
Anual sobre Pesquisa e Educação em Estudos de Defesa e Segurança, em Santiago do Chile, o Ministro disse que "somente em 1988, o Brasil passara a viver em regime de Direito democrático [...] [com] a conseqüente abolição dos conceitos de segurança nacional [...]" (QUINTÃO, 2003, p. 4). O próprio Ministro Viegas, em sua carta de demissão, encarregar-se-ia de desdizer Quintão. Nessa carta, o demissionário enfatizou a existência de setores castrenses na cúpula militar adeptos de conceitos oriundos da Doutrina de Segurança Nacional.
Por sinal, convém não esquecer que a Lei de Segurança Nacional (LSN), de 1983, braço jurídico da Doutrina de Segurança Nacional, continua em vigor. Trata-se de lei de proteção política do Estado, ou melhor, de um Estado autoritário (ZAVERUCHA, 2005, p. 210). FHC chegou a criar uma comissão para substituir a LSN, mas desistiu. No Congresso Nacional encontram-se emendas de parlamentares do PT propondo o fim da LSN. Nem o PT nem o Presidente Lula iniciaram um debate sobre o tema. A demissão de Viegas e a assunção de Alencar são um incentivo para essas propostas continuarem em sono profundo.

Jorge Zaverucha (jorgezaverucha@uol.com.br) é Doutor em Ciência Política pela University of Chicago, Professor da Universidade Federal de Pernambuco (UFPE) e bolsista do Conselho Nacional de Desenvolvimento Científico e Tecnológico (CNPq).

\section{REFERÊNCIAS BIBLIOGRÁFICAS}

ÁLVARES, E. 2000. Entrevista. Época, São Paulo, 16.jan.

ALVES, M. M. 1999. Gentes da guerra. O Globo, Rio de Janeiro, 29.dez.

AZEREDO, Z. 1999. Posse em clima de consternação e contrariedade. Jornal de Brasília, 22.dez.

2000. Ministro assume prometendo aumento. Jornal de Brasília, 25.jan.

BRASIL. Ministério da Defesa. Exército Brasileiro. 2004. Missões no exterior e cursos. Informex, n. 45, 28.set. Disponível em : http:/ /www.exercito.gov.br/05Notici/Informex/ 2004/infor045.htm. Acesso em : 28.abr.2006.

BOECHAT, R. 2002. Coluna. Jornal do Brasil, Rio de Janeiro, $1^{\circ}$.mar.

CARDOSO, F. H. 2000. Discurso na cerimônia de apresentação dos oficiais generais recémpromovidos. Brasília : Brasil. Presidência da República.

CARVALHO, J. \& DAMÉ, L. 2004. "Nada tenho com o passado", diz Alencar ao tomar posse na Defesa. O Globo, Rio de Janeiro, 9.nov.

CARVALHO, J. M. 1999. Vargas e os militares. In : PANDOLFI, D. (org.). Repensando o Estado Novo. Rio de Janeiro : Fundação Getúlio Vargas.
CASTRO, C. 2000. The Military Politics in Brazil: 1964-2000. Working Paper Series CBS10-00H. Oxford : University of Oxford Centre for Brazilian Studies.

CORRÊA, M. 2004. As fragilidades do chefe. Correio Braziliense, Brasília, 21.nov.

CRUVINEL, T. 2001. Panorama político. O Globo, Rio de Janeiro, 5.out.

DAY, M. 2002. Changing Masters, Changing Priorities. Jane's Defence Weekly, 7.May.

ÉBOLI, E. 2002. Tucano tenta destituir tucano. O Globo, Rio de Janeiro, 11.mar.

FRANÇA, W. 1999. Ex-Senador assume Defesa. Folha de S. Paulo, 11.jul.

. 2000. Civil assume Infraero após 17 anos. Folha de S. Paulo, 20.abr.

FRANÇA, W. \& NAHASS, D. 2000. Após reajuste generais não aplaudem FHC. Folha de $S$. Paulo, 13.dez.

FREITAS, J. 2004. Mistérios no céu. Folha de S. Paulo, 21.nov.

HITE, K. \& CESARINI, P. 2004. Autho-ritarian Legacies and Democracy in Latin America and Southern Cone. Notre Dame: University of Notre Dame. 
JUNGBLUT, C. 2002. FH afirma que tentou fazer tudo pelas Forças Armadas e agradece a colaboração. O Globo, Rio de Janeiro, 19.set.

KRAMER, D. 2000. Coluna. Jornal do Brasil, Rio de Janeiro, 4.jan.

2004. Os embates de Viegas. O Estado de S. Paulo, 6.nov.

KRIEGER, G. 2002. Informe JB. Jornal do Brasil, Rio de Janeiro, 18.set.

LACERDA, A. \& CARVALHO, J. 1998. Pasta pode ganhar mais poder. Jornal do Brasil, Rio de Janeiro, 25.mar.

LEALI, F. 1999. Ministro sob fogo cruzado. Jornal do Brasil, Rio de Janeiro, 29.dez.

2000. Quintão fez viagem particular pela FAB. Jornal do Brasil, Rio de Janeiro, 22.jan.

LIMA, M. 1999. Senado aprova indicação para STM de General que invadiu CSN. O Globo, Rio de Janeiro, 21.out.

LOPES, R. 2000. Sem defesa. Folha de S. Paulo, 11.maio.

MARQUES, H. 2002. Problemas na caserna. Jornal do Brasil, Rio de Janeiro, 7.jul.

MARTINS, F. 1999. Crônica de uma crise militar anunciada. Jornal de Brasília, 19.dez.
MEIRELES, A. 1999. Defesa aberta. Istoé, São Paulo, 6.out.

MENEZES, C. 2004. A força dos generais. Veja, São Paulo, 17.nov.

PATURY, F. 1999. Brasil paga "tropa" de 248 no exterior. Folha de S. Paulo, 21.out.

PINTO, P. S. 2002. A boa vida das missões militares. Correio Braziliense, Brasília, 8.fev.

RODRIGUES, F. 2001. Há "sexo consentido" entre índia e militar, diz Quintão. Folha de S. Paulo, 21.mar.

QUINTÃO, G. M. C. 2003. Palestra. Palestra proferida na VI Conferência Anual sobre Pesquisa e Educação em Estudos de Defesa e Segurança, realizada em 27 e 30 de outubro, em Santiago do Chile. Disponível em : http:// www.ndu.edu/chds/redes2003/plenaysessions/plenary-i/2.\%20quintao.doc. Acesso em : 28.abr.2006.

VILLA, M. A. 2004. Os militares e a República. Folha de S. Paulo, 15.nov.

ZAVERUCHA, J. 2000. Frágil democracia : Collor, Itamar, FHC e os militares (1990-1998). Rio de Janeiro : Civilização Brasiliense. 2005. FHC, Forças Armadas e polícia: entre o autoritarismo e a democracia. Rio de Janeiro : Record.

\section{OUTRAS FONTES}

Arquivos do regime militar serão abertos. 2000. O Estado de S. Paulo, 18.maio.

Discursos pedem impeachment e a volta ao poder. 1999. O Estado de S. Paulo, 29.dez.

Élcio Álvares $x$ Forças Armadas. 1999. Folha de S. Paulo, 18.dez.

Exército brasileiro tem mais general que os EUA. 2004. Jornal do Commercio, 5.set.

Exército corta na carne. 2002. Jornal do Brasil, Rio de Janeiro, 12.jul.

FHC criou prazo de 50 anos para papéis ultrasecretos. 2004. O Estado de S. Paulo, 12.nov.
Holofotes. 1999. Veja, São Paulo, 28.abr.

Legislativo é acompanhado. 2002. Diário de Pernambuco, Recife, 17.nov.

Militares dão sinal amarelo ao governo Fernando Henrique. 1999. Tribuna da Imprensa, Rio de Janeiro, 29.dez.

Planalto adota estratégia do silêncio e prefere ignorar ato. 1999. O Estado de S. Paulo, 29.dez.

Presidente faz nomeação de vice que FHC planejou. 2004. Valor Econômico, São Paulo, 5-7.nov. 
Promotor rebate crítica de Quintão sobre viagens. 2000. O Estado de S. Paulo, 23.jan.

QUINTÃO, G. 2003. Entrevista concedida a Jorge Zaverucha. Santiago do Chile, 29.out.

Quintão: Ministério Público é exibicionista. 2000. O Globo, Rio de Janeiro, 21.jan.

RBJID. s/d. Representação Brasileira na Junta Interamericana de Defesa. Disponível em : http://www.rbjid.com. Acesso em : 28.abr.2006.
Reforço para a Amazônia. 2003. O Estado de S. Paulo, 28.jul.

VIEGAS FILHO, J. 2004. Carta do Ministro José Viegas Filho ao Presidente Luiz Inácio Lula da Silva. Brasília, 04.nov. Disponível em : http://www.defesa.gov.br/ enternet/sitios/internet/temp/carta.pdf. Acesso em : 02.jun.2006. 